\title{
Gender disparities in screening for congenital hypothyroidism using thyroxine as a primary
}

\section{screen}

\author{
Lenore DeMartino', Rebecca McMahon', Michele Caggana' and Norma P Tavakoli, ${ }^{1,2}$ \\ ${ }^{1}$ Division of Genetics, Wadsworth Center, New York State Department of Health, Albany, New York, USA and \\ 2Department of Biomedical Sciences, School of Public Health, State University of New York, Albany, New York, USA

\begin{abstract}
Objective: Newborn screening for congenital hypothyroidism (CH) is based on testing for the markers thyroxine (T4) and/or thyroid-stimulating hormone (TSH). Diagnosis of $\mathrm{CH}$ is complicated because many factors affect the levels of these hormones including infant birth weight, prematurity and age at specimen collection. We investigated whether the sex of the newborn affected the levels of T4 and TSH and consequently the outcome of newborn screening.

Design: In New York State, the Newborn Screening program initially tests all infants for T4 and any baby with a result in the lowest $10 \%$ is triaged for TSH screening. We analyzed data from 2008 to 2016 to determine mean and median T4 and TSH values and how these results correlate with the sex of infants who are reported as borderline, referred and confirmed with $\mathrm{CH}$.

Methods: T4 and TSH concentrations in dried blood spots were measured using commercially available fluoroimmunoassays.

Results: From 2008 to 2016, of the 2.4 million specimens tested for thyroxine, $51.5 \%$ were from male and $48.5 \%$ were from female infants. Male infants constituted $60 \%$ of specimens triaged for TSH testing, $64.9 \%$ of repeat requests and $59.6 \%$ of referrals, but only $49 \%$ of confirmed $\mathrm{CH}$ cases. The mean and median T4 values were lower (a difference of approximately $0.8-1.1 \mu \mathrm{g} / \mathrm{dL}$ each year) and the median TSH values were higher in male compared to female infants. Conclusions: Natural differences in thyroid hormone levels in male and female infants leads to male infants being disproportionately represented in the false-positive category.
\end{abstract}

\section{Introduction}

Newborn screening for congenital hypothyroidism $(\mathrm{CH})$ is crucial in detecting this common endocrine disorder that untreated may result in intellectual disability and growth retardation. Screening strategies are based on detecting low thyroxine (T4), or, elevated thyroid-stimulating hormone (TSH) or, a combination of both $(1,2,3)$. Factors other than $\mathrm{CH}$ disease that affect $\mathrm{T} 4$ and $\mathrm{TSH}$ values will contribute to false-positive and -negative results if they are not considered in the screening algorithm. For example, within the first 1-2 days after birth, there is a

www.eje-online.org https://doi.org/10.1530/EJE-18-0399
C) 2018 European Society of Endocrinology Printed in Great Britain physiological surge in TSH which then normalizes $(2,4,5)$. Consequently, if a specimen is collected within the first $24 \mathrm{~h}$ after birth and no consideration is made for time of collection, an elevated TSH will indicate $\mathrm{CH}$ and the baby will be referred unnecessarily. As a result, many programs have different cut-offs for TSH if the specimen was collected within the first $24 \mathrm{~h}$ after birth. Other factors that affect T4 and TSH values are birth weight and prematurity (6). Low birth weight (LBW) and preterm infants have low total T4 values $(7,8,9)$. A significant number of 
infants who are admitted to NICU, especially extremely LBW, ill or premature infants, exhibit a delayed TSH rise $(10,11,12,13,14)$ due to the immaturity of the hypothalamic-pituitary axis. Because TSH is lower in premature infants than in full-term infants (15), the initial newborn screen cannot be relied upon to detect $\mathrm{CH}$ in premature infants. This leads to the recommendation that thyroid function should be monitored in LBW, preterm and babies admitted to the NICU subsequent to the initial newborn screen for at least 4-6 weeks, irrespective of weight $(10,12,16)$.

The New York State (NYS) Newborn Screening Program (NBSP) initially screens all infants for T4 and any baby with a result in the lowest $10 \%$ is then screened for TSH. Infants with low T4 and elevated TSH are referred for follow-up diagnostic testing. An additional specimen is requested for infants with low T4 and normal TSH or normal T4 and slightly elevated TSH. We investigated whether in addition to the time of specimen collection, birth weight and prematurity, whether the sex of the infant would also affect $\mathrm{T} 4$ and TSH values and how this would influence referral rates of male and female infants. Any factor that influences T4 and TSH values in infants should be a consideration in selecting an algorithm for $\mathrm{CH}$ screening and setting cut-off values.

\section{Subjects and methods}

From 2008 to 2016, the NYS NBSP screened approximately 2.2 million babies for $\mathrm{CH}$. In NYS, it is recommended that a blood specimen be collected via a heel stick from newborns on a Guthrie card 24-48 h after birth and sent to the NBSP with mother and infant demographic information. Specimens are required to be shipped overnight at ambient temperature. Three millimeter dried blood spots were punched into 96-well plates. T4 concentration in dried blood spots was measured using the AutoDELFIA neonatal thyroxine kit (Perkin Elmer). Each T4 assay was comprised of two 96-well plates, each containing 87 patient specimens. The specimens with the lowest $10 \%$ values for $\mathrm{T} 4$ for each assay were triaged for TSH testing. Approximately 298000 infants were screened for TSH using the AutoDELFIA neonatal hTSH kit (Perkin Elmer). Infants with abnormal results were referred for follow up diagnostic testing or if a borderline result was obtained, a repeat specimen was requested. Figure 1 is a schematic of the current $\mathrm{CH}$ testing algorithm.

\section{Statistical analysis}

Differences in $\mathrm{T} 4$ mean values for male and female infants were assessed using one-way ANOVA, and differences in the numbers of male and female infants referred reported as borderline or triaged for TSH testing were assessed using the Chi-square test. A $P$ value of $<0.05$ was considered statistically significant.

\section{Human subjects}

The manuscript is a retrospective case report that does not require institutional review board approval at our institution (Wadsworth Center, NYSDOH). All procedures performed in studies involving human participants were in accordance with the ethical standards of the institutional and national research committee and with the 1964 Helsinki declaration and its later amendments or comparable ethical standards.

\section{Results}

Amongst the 2.4 million specimens from 2.2 million babies tested for T4, 51.5\% were from male and $48.5 \%$ were from female infants (Table 1). First tier screening was performed for $\mathrm{T} 4$ and the specimens with the lowest $10 \% \mathrm{~T} 4$ values were triaged for TSH testing. Of the specimens triaged to be screened for TSH, $60 \%$ were from male and $40 \%$ were from female infants. Repeat specimens were requested for 21407 male and 11569 female infants due to borderline T4 or TSH results (Table 1). Following receipt of repeat specimens for these infants, 625 male and 340 female infants were diagnosed with $\mathrm{CH}$, or 'other $\mathrm{CH}^{\prime}$ '. The 'other $\mathrm{CH}^{\prime}$ ' category included: possible $\mathrm{CH}$ disease, maternal medication and maternal TSH-blocking antibodies, thyroid disease of other etiology (e.g. Down syndrome which is associated with thyroid dysfunction) and a disease not on the newborn screening panel.

From 2008 to 2016 based on the NYS screening algorithm, 4114 male and 2791 female infants were referred (Table 1). Follow-up of referred infants confirmed $\mathrm{CH}$ in $718(49.0 \%)$ male and $747(51.0 \%)$ female infants over the 9-year period (Table 2). Confirmed $\mathrm{CH}$ cases included, primary $\mathrm{CH}$ (generally with low T4, elevated TSH), secondary CH (low T4, normal TSH) and compensated $\mathrm{CH}$ (slightly low to normal $\mathrm{T} 4$ and elevated TSH). Of the 889 cases of primary $\mathrm{CH}, 370$ (41.6\%) were male and 518 (58.3\%) were female infants 


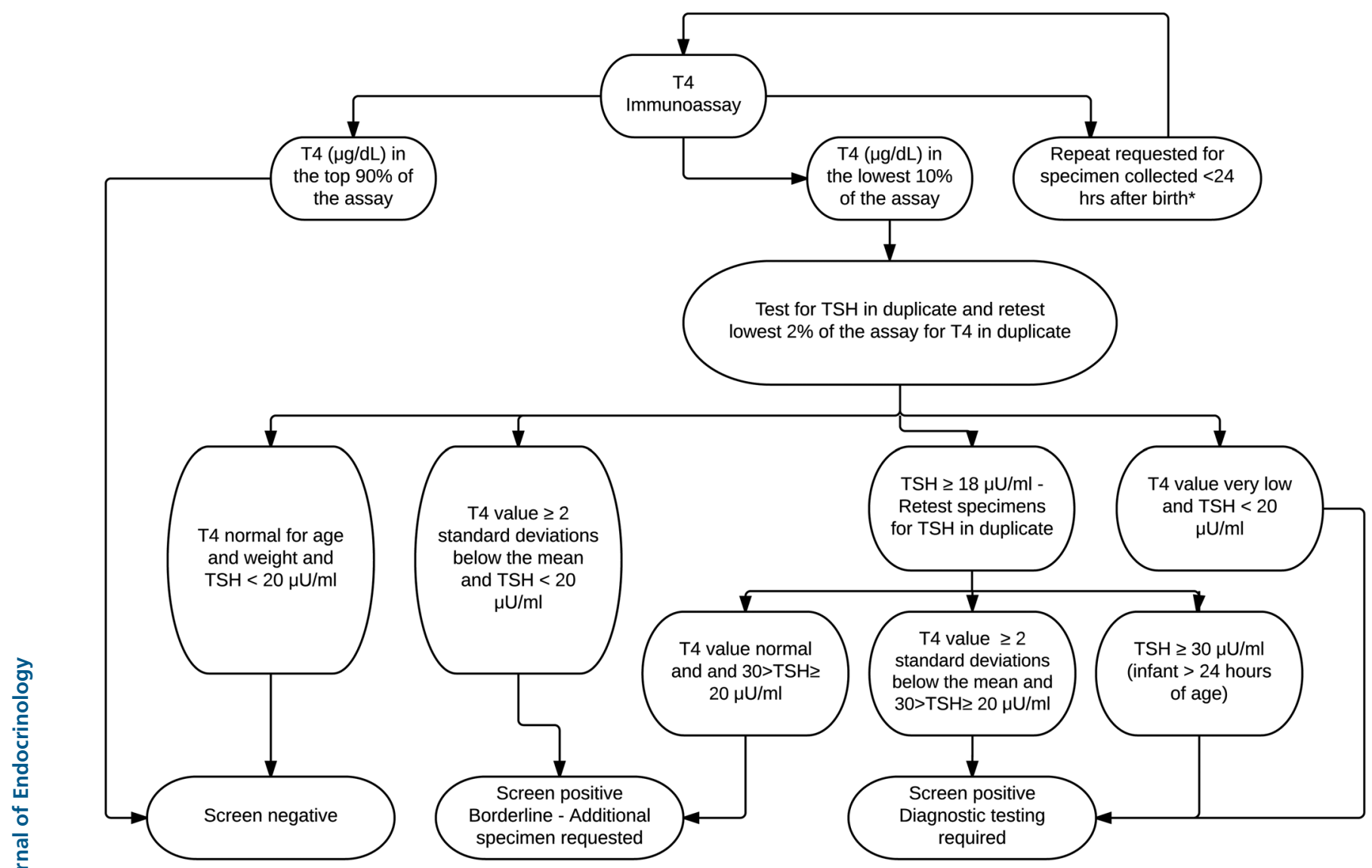

Figure 1

Current NYS screening algorithm for $\mathrm{CH} .{ }^{*} \mathrm{~A}$ repeat specimen is requested when a specimen collected on day of birth (DOB) is received but the specimen is nevertheless tested. If the TSH value of a DOB specimen is $\geq 150 \mu \mathrm{U} / \mathrm{mL}$, the infant is immediately referred for $\mathrm{CH}$. For a non-DOB specimen, an infant with a TSH value $\geq 100 \mu \mathrm{U} / \mathrm{mL}$ is immediately referred. T4, thyroxine; TSH, thyroid-stimulating hormone.

and of the 49 cases of secondary $\mathrm{CH}, 27$ (55.1\%) were male and 22 (44.9\%) were female infants. Five hundred fifty four (64.3\%) male and 307 (35.7\%) female cases were closed as 'other $\mathrm{CH}^{\prime}$ (Table 2). Four hundred sixty five (64.9\%) male cases were closed as possible $\mathrm{CH}$, whereas only 252 (35.1\%) female cases were closed as possible $\mathrm{CH}$ (Table 2). Cases are closed as possible $\mathrm{CH}$ due to hypothyroxinemia or hyperthyrotropinemia

Table 1 Numbers of different categories of specimens tested, and babies reported as borderline or referred for $\mathrm{CH}$ from 2008 to 2016.

\begin{tabular}{lr} 
& \multicolumn{1}{c}{ Total } \\
\hline Specimens tested & 2,366384 \\
Babies, $n$ & 2,178705 \\
Specimens from NBW babies & 1,994133 \\
Specimens from LBW babies & 278174 \\
DOB specimens tested & 46385 \\
Borderline & 23963 \\
$\quad$ Low T4/normal TSH & 9023 \\
$\quad$ Normal T4/slightly elevated TSH & 32986 \\
$\quad$ Total & 6907 \\
Total referred
\end{tabular}

$\begin{array}{r}\text { Male } \\ \hline 1,219602(51.5 \%) \\ 1,116419(51.2 \%) \\ 1,031141(51.7 \%) \\ 135902(48.9 \%) \\ 24865(53.6 \%) \\ 15109(63.1 \%) \\ 6298(69.8 \%) \\ 21407(64.9 \%) \\ 4114(59.6 \%) \\ \hline\end{array}$

\begin{tabular}{r}
\multicolumn{1}{c}{ Female } \\
\hline $1,146530(48.5 \%)$ \\
$1,062097(48.7 \%)$ \\
$962853(48.3 \%)$ \\
$142200(51.1 \%)$ \\
$21502(46.4 \%)$ \\
$8845(36.9 \%)$ \\
$2724(30.2 \%)$ \\
$11569(35.1 \%)$ \\
$2791(40.4 \%)$
\end{tabular}

DOB, day of birth ( $<24$ h); LBW, low birth weight ( $<2500$ g); NBW, normal birth weight ( $\geq 2500$ g; $\geq 24 h, \leq 14$ day old babies); T4, thyroxine; TSH, thyroid-stimulating hormone. 
Table 2 Numbers of confirmed $\mathrm{CH}$, possible $\mathrm{CH}$, 'other $\mathrm{CH}^{\prime}$ and TBG deficiency from 2008 to 2016.

\begin{tabular}{|c|c|c|c|}
\hline & Male & Female & Total \\
\hline Confirmed $\mathrm{CH}$ & 718 (49\%) & $747(51 \%)$ & 1,466 \\
\hline Primary $\mathrm{CH}$ & $370(41.7 \%)$ & $518(58.3 \%)$ & 889 \\
\hline Secondary $\mathrm{CH}$ & $27(55.1 \%)$ & $22(44.9 \%)$ & 49 \\
\hline Compensated $\mathrm{CH}$ & $321(60.8 \%)$ & $207(39.2 \%)$ & 528 \\
\hline 'Other $\mathrm{CH}^{\prime}$ & $554(64.3 \%)$ & $307(35.7 \%)$ & 861 \\
\hline Possible $\mathrm{CH}$ & $465(64.9 \%)$ & $252(35.1 \%)$ & 717 \\
\hline Maternal medications & $16(51.6 \%)$ & $15(48.4 \%)$ & 31 \\
\hline Maternal antibody & $15(55.6 \%)$ & $12(44.4 \%)$ & 27 \\
\hline \multicolumn{4}{|l|}{ No disease } \\
\hline TBG deficiency & $275(89 \%)$ & $34(11 \%)$ & 309 \\
\hline
\end{tabular}

'Other $\mathrm{CH}^{\prime}$ included: possible $\mathrm{CH}$ disease, maternal medication and maternal TSH-blocking antibodies, thyroid disease of other etiology (e.g. Down syndrome which is associated with thyroid dysfunction), and a disease not on the newborn screening panel.

$\mathrm{CH}$, congenital hypothyroidism; TBG, thyroxine-binding globulin deficiency.

of prematurity or persistent hypothyroxinemia or hyperthyrotropinemia.

From 2008 to 2016, thyroxine-binding globulin (TBG) deficiency was reported in 275 male infants and 34 female infants (Table 2). The expectation is that there is significant underreporting of TBG deficiency to the NBSP because this condition is generally non-harmful.

We hypothesized that the reason more male infants were triaged for TSH testing was reported with borderline results and were referred was because there were differences between T4 and TSH concentrations in male and female infants. Therefore, we calculated yearly mean and median values for T4 and TSH for male and female infants. The mean and median T4 values were lower in male than female infants (a difference of approx. 0.8-1.1 $\mu \mathrm{g} / \mathrm{dL}$ each year) as evidenced by the mean yearly values (Fig. 2A) $(P<0.0000001)$ and the normal distribution curves (Fig. 2B is an example from 2014). The lower mean and median T4 values in male infants were not due to low birth weight since male infants had higher mean and median birth weights than female infants, and there were fewer low birth weight (LBW) male infants than female infants (Tables 1 and 3). LBW was defined as babies who weighed less than $2500 \mathrm{~g}$. The lower mean and median T4 values were also not due to more specimens from male babies being collected within the first $24 \mathrm{~h}$ after birth because when T4 values from these babies were not included in T4 calculations, the mean and median T4 values remained lower in male than female infants (data not shown). Mean TSH values were similar in male and female infants but median values for male infants were higher (Fig. 2C).
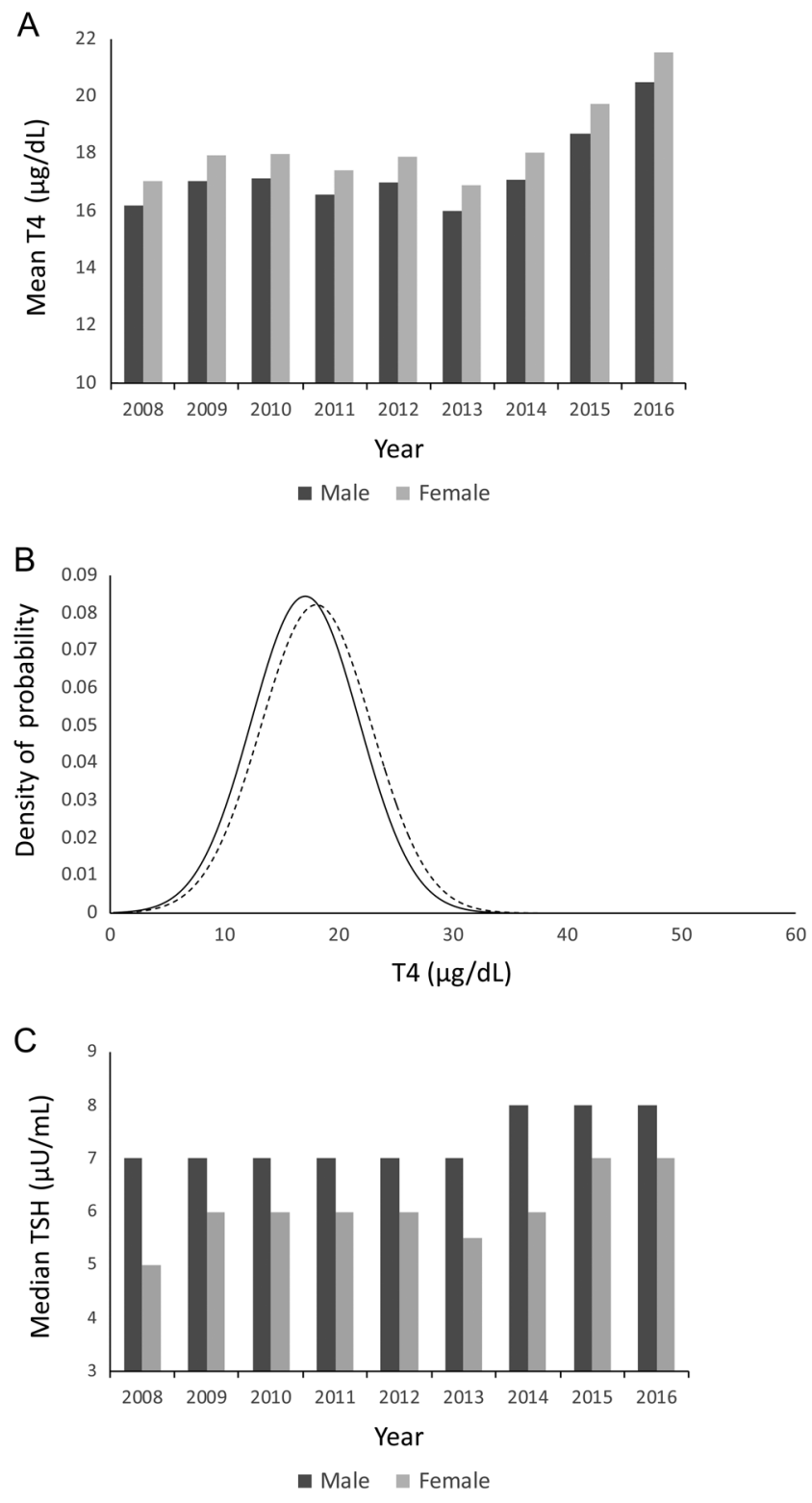

Figure 2

Yearly mean T4 values for male and female infants. (A) Yearly mean T4 values are lower in male than female infants $(P<0.0000001)$. A similar pattern was observed for yearly median T4 values (data not shown). Normal distribution curve for T4 values for male and female infants in 2014. (B) The normal distribution of T4 for male infants is represented by a black line, for female infants it is represented by a dashed black line. The normal distribution curve of T4 values for male infants are shifted to the left compared to female infants. This data represents 2014. A similar shift is seen for all other years from 2008 to 2016. Yearly median TSH values for male and female infants. (C) Yearly median TSH values are higher in male than female infants. 
Table 3 Mean and median birth weight of male and female infants from 2008 to 2016.

\begin{tabular}{|c|c|c|c|}
\hline \multirow[b]{2}{*}{ Year } & \multicolumn{3}{|c|}{ Mean weight (g) } \\
\hline & Male & Female & Difference \\
\hline 2008 & 3323.0 & 3208.5 & 114.5 \\
\hline 2009 & 3321.8 & 3204.5 & 117.3 \\
\hline 2010 & 3321.3 & 3203.4 & 117.9 \\
\hline 2011 & 3321.9 & 3201.3 & 120.6 \\
\hline 2012 & 3326.0 & 3206.4 & 119.6 \\
\hline 2013 & 3328.0 & 3212.1 & 115.9 \\
\hline 2014 & 3331.6 & 3216.1 & 115.5 \\
\hline 2015 & 3330.8 & 3213.2 & 117.6 \\
\hline 2016 & 3326.5 & 3206.6 & 119.9 \\
\hline
\end{tabular}

\begin{tabular}{|c|c|c|}
\hline \multicolumn{3}{|c|}{ Median weight $(\mathrm{g})$} \\
\hline Male & Female & Difference \\
\hline 3365 & 3247 & 118 \\
\hline 3365 & 3245 & 120 \\
\hline 3365 & 3240 & 125 \\
\hline 3365 & 3240 & 125 \\
\hline 3370 & 3245 & 125 \\
\hline 3370 & 3250 & 120 \\
\hline 3370 & 3250 & 120 \\
\hline 3370 & 3250 & 120 \\
\hline 3369 & 3240 & 129 \\
\hline
\end{tabular}

The specificity and positive predictive value (PPV) of the $\mathrm{CH}$ screening method were calculated. We did not attempt to calculate the sensitivity or negative predictive value of the screening method as the program rarely receives feedback regarding false-negative cases. Although the specificity of the $\mathrm{CH}$ screening method is similar in male and female infants (99.7\% vs $99.8 \%)$, the PPV is notably lower in male infants than female infants $(17.54 \%$ vs $26.83 \%)$.

\section{Discussion}

Having tested 2.2 million infants from 2008 to 2016 for $\mathrm{CH}$, our data show that male infants have a lower mean (and median) T4 and higher median TSH than female infants despite having a higher mean and median birth weight. If there was no difference between the sexes, the expectation would be that female infants would have lower T4 values and higher TSH values, since their mean and median birth weight are lower and birth weight is known to affect T4 and TSH values. Higher median TSH has been reported previously in male babies (17), as well as, in male adults (18).

As a result of the difference between male and female infants in their T4 and TSH hormone levels, in our program a higher percentage of male than female infants were triaged for TSH testing $(60 \%$ vs $40 \%)(P<0.0001)$, a higher number of repeat specimens from male infants were requested $(64.9 \%$ vs $35.1 \%)(P<0.0001)$ and a higher number of male infants were referred $(59.6 \%$ vs $40.4 \%)(P<0.0001)$ (Table 1$)$. Yet, primary $\mathrm{CH}$ has a higher incidence in female infants and overall there are a higher number of confirmed $\mathrm{CH}$ cases in females (Table 2). However, a higher number of cases of male infants were closed as possible $\mathrm{CH}$ (Table 2). These infants have hypothyroxinemia or hyperthyrotropinemia of prematurity or persistent hypothyroxinemia or hyperthyrotropinemia and are either on treatment or continue to be monitored. Both hypothyroxinemia and hyperthyrotropinemia of prematurity resolve with advancing postnatal age, although they may require T4 replacement for up to 1 year (19). In NYS a larger number of male infant cases are closed as possible $\mathrm{CH}$ seemingly due to the borderline results in these babies indicating subclinical hypothyroidism/mild disease or transient hypothyroidism. Babies with possible $\mathrm{CH}$ are monitored regularly and some are on treatment. Longterm follow-up of these babies including information on their physical and cognitive development would be useful to determine whether these cases are true cases of $\mathrm{CH}$ and require treatment or whether they are transient. The current recommendation for babies whose $\mathrm{CH}$ status is not certain but who are on treatment is to discontinue treatment at three years of age and determine whether they remain hypothyroid $(1,20,21)$. Unfortunately, our program does not have the ability to follow these babies until three years of age and therefore the outcome of the trial-off therapy is not available to us. In addition, it is not evident whether the recommendation is followed.

Our program detected a total of 309 cases of TBG deficiency (Table 2). Male babies constituted $89 \%$ of these cases. TBG deficiency is an X-linked condition and is fairly common in male infants ( 1 in 2400) and approximately ten-fold less frequent in females $(22,23)$. The incidence in our male populations was lower ( 1 in 4059 ) because there is underreporting of this condition to the program: either TBG testing was not done or if it was done, the result was not reported to the program. TBG deficiency does not cause thyroid disease but it does hinder the interpretation of thyroid function tests because these babies have low total T4 but normal free T4 and TSH (15). It is necessary to rule out TBG deficiency so that the baby is not unnecessarily evaluated and treated for $\mathrm{CH}$. Unlike programs that use T4 as the primary screen for $\mathrm{CH}$, programs that use TSH miss TBG deficient infants (1). 
Using our algorithm, male infants are disproportionately represented in the false positive category even though incidence of $\mathrm{CH}$ in male infants is marginally lower. In a national data set from 1991 to 2000, the female to male ratio of $\mathrm{CH}$ was reported to be 1.56 (24). Our data shows that the female-to-male ratio of primary $\mathrm{CH}$ is 1.47 while the overall $\mathrm{CH}$ ratio is 1.09 and the ratio of possible $\mathrm{CH}$ is 0.57 . Our results indicate that in addition to considering different cut-offs based on time of specimen collection and infant's birth weight, the sex of the infant may also be a consideration. It would be interesting to determine whether programs that use a first tier TSH test to screen for $\mathrm{CH}$ also have a higher number of false positive results for males. Our expectation is that they will have a higher false positive rate because median TSH values for males are higher in male infants than female infants. Therefore, if the same cut-off is used for males and females, a higher number of male infants will cross the threshold value. From 2008 to 2016 our program requested a repeat specimen for 9023 specimens that were borderline because of normal T4 values and slightly elevated TSH values. Of the 9023 infants, 6298 (69.8\%) were male and 2724 (30.2\%) were female infants (Table 2). Five thousand nine hundred and eighty three of the male borderline cases and 2589 of the female borderline cases were closed as no disease indicating that even in infants with normal T4, a higher number of male infants fell into an abnormal category requiring an additional specimen.

The consequence of lower T4 and higher TSH values in male infants is that significantly increased number of recalls and follow-up tests are required for male infants. Most of the male babies were in the borderline range for either or both T4 and TSH and many cases were closed as possible disease (Table 1). Unfortunately, the status of these cases is unclear. Because, they may be on treatment or are just being followed and those who are on treatment may have potentially transient or mild $\mathrm{CH}$ which may resolve by 3 years of age. Additional data are needed to determine whether early treatment in these babies is beneficial. Our data are consistent with programs who have decreased their TSH cut-off value and then found an increased in incidence of $\mathrm{CH}$ with the female to male ratio of presumptive positive cases decreasing (25). Cases of infants with transient hypothyroidism have a lower female-to-male ratio than cases of permanent $\mathrm{CH}$ (26). Additional studies are needed to determine whether these borderline T4 and TSH values in male infants indicate treatment requiring $\mathrm{CH}$ disease or whether male infants have naturally different ranges, in which case NBS programs should investigate setting different cut-off ranges for T4 and TSH for male and female infants. Although setting different cut-offs will complicate the $\mathrm{CH}$ algorithm, it will decrease the number of false positive screens for male infants.

\section{Declaration of interest}

The authors declare that there is no conflict of interest that could be perceived as prejudicing the impartiality of this study.

\section{Funding}

Funding for newborn screening in NYS is provided by the State of NY.

\section{Author contribution statement}

$L D$ and $R M$ were involved in acquisition of data and revising the manuscript. M C was involved in interpreting data and revising the manuscript. N P T was involved in design of the work, analysis and interpreting of data and drafting and finalizing the manuscript.

\section{Acknowledgements}

The authors would like to thank past and present members of the NYS NBSP's Immunoassay and Accessioning Laboratory for performing T4 and TSH testing and the follow-up unit for performing follow-up of infants with $\mathrm{CH}$.

\section{References}

1 American Academy of Pediatrics, Rose SR, Section on Endocrinology and Committee on Genetics, American Thyroid Association, Brown RS, Public Health Committee, Lawson Wilkins Pediatric Endocrine Society, Foley T, Kaplowitz PB, Kaye CI, et al. Update of newborn screening and therapy for congenital hypothyroidism. Pediatrics 2006117 2290-2303. (https://doi.org/10.1542/peds.20060915)

2 LaFranchi SH. Newborn screening strategies for congenital hypothyroidism: an update. Journal of Inherited Metabolic Disease 201033 (Supplement 2) S225-S233. (https://doi.org/10.1007/s10545010-9062-1)

3 Ford G \& LaFranchi SH. Screening for congenital hypothyroidism: a worldwide view of strategies. Best Practice and Research Clinical Endocrinology and Metabolism 201428 175-187. (https://doi. org/10.1016/j.beem.2013.05.008)

4 Fisher DA \& Odell WD. Acute release of thyrotropin in the newborn. Journal of Clinical Investigation 196948 1670-1677. (https://doi. org/10.1172/JCI106132)

5 Kawahara K \& Yokoya S. Original establishment of reference intervals of thyrotropin and free thyroid hormones during the first week of life. Clinical Pediatric Endocrinology 200211 1-9. (https://doi. org/10.1297/cpe.11.1)

6 Hyman SJ, Novoa Y \& Holzman I. Perinatal endocrinology: common endocrine disorders in the sick and premature newborn. Pediatric Clinics of North America 201158 1083-1098. (https://doi. org/10.1016/j.pcl.2011.07.003)

7 Kok JH, Hart G, Endert E, Koppe JG \& De Vijlder JJM. Normal ranges of T4 screening values in low birthweight infants. Archives of Disease in Childhood 198358 190-194. (https://doi.org/10.1136/ adc.58.3.190)

8 Van Wassenaer AG, Kok JH, Briet JM, Pijning AM \& de Vijlder JJ. Thyroid function in very preterm newborns: possible implications. Thyroid 19999 85-91. (https://doi.org/10.1089/thy.1999.9.85) 
9 Carrascosa A, Ruiz-Cuevas P, Potau N, Almar J, Salcedo S, Clemente M $\&$ Yeste D. Thyroid function in seventy-five healthy preterm infants thirty to thirty-five weeks of gestational age: a prospective and longitudinal study during the first year of life. Thyroid $2004 \mathbf{1 4}$ 435-442. (https://doi.org/10.1089/105072504323150741)

10 Hyman SJ, Greig F, Holzman I, Patel A, Wallach E \& Rapaport R. Late rise of thyroid stimulating hormone in ill newborns. Journal of Pediatric Endocrinology and Metabolism 200720 501-510. (https://doi. org/10.1515/JPEM.2007.20.4.501)

11 Bijarnia S, Wilcken B \& Wiley VC. Newborn screening for congenital hypothyroidism in very-low-birth-weight babies: the need for a second test. Journal of Inherited Metabolic Disease 201134 827-833. (https://doi.org/10.1007/s10545-011-9286-8)

12 Zung A, Yehieli A, Blau A \& Almashanu S. Characteristics of delayed thyroid-stimulating hormone elevation in neonatal intensive care unit newborns. Journal of Pediatrics 2016178 135-140. (https://doi. org/10.1016/j.jpeds.2016.07.022)

13 Cavarzere P, Camilot M, Popa FI, Lauriola S, Teofoli F, Gaudino R, Vincenzi M \& Antoniazzi F. Congenital hypothyroidism with delayed TSH elevation in low-birth-weight infants: incidence, diagnosis and management. European Journal of Endocrinology 2016175 395-402. (https://doi.org/10.1530/EJE-15-1233)

14 Heather NL, Hofman PL, de Hora M, Carll J, Derraik JG \& Webster D. Evaluation of the revised New Zealand national newborn screening protocol for congenital hypothyroidism. Clinical Endocrinology 2016 86 431-437. (https://doi.org/10.1111/cen.13250)

15 Diaz A \& Lipman Diaz EG. Hypothyroidism. Pediatrics in Review 2014 35 336-349. (https://doi.org/10.1542/pir.35-8-336)

16 Silva SA, Chagas AJ, Goulart EM, Silva GA, Marçal LV, Gomes MN \& Alves VM. Screening for congenital hypothyroidism in extreme premature and/or very low birth weight newborns: the importance of a specific protocol. Journal of Pediatric Endocrinology and Metabolism 201023 45-52. (https://doi.org/10.1515/ JPEM.2010.23.1-2.45)

17 Korada M, Pearce MS, Avis E, Turner S \& Cheetham T. TSH levels in relation to gestation, birth weight and sex. Hormone Research 200972 120-123. (https://doi.org/10.1159/000232165)
18 Hadlow NC, Rothacker KM, Wardrop R, Brown SJ, Lim EM \& Walsh JP. The relationship between TSH and free T4 in a large population is complex and nonlinear and differs by age and sex. Journal of Clinical Endocrinology and Metabolism 201398 2936-2943. (https://doi.org/10.1210/jc.2012-4223)

19 La Gamma EF, Korzeniewski SJ, Ballabh P \& Paneth N. Transient hypothyroxinemia of prematurity. Neoreviews 201617 e394-e402. (https://doi.org/10.1542/neo.17-7-e394)

20 Davy T, Daneman D, Walfish PG \& Ehrlich RM. Congenital hypothyroidism: the effect of stopping treatment at 3 years of age. American Journal of Diseases of Children 1985139 1028-1030. (https:// doi.org/10.1001/archpedi.1985.02140120074031)

21 Eugster EA, LeMay D, Zerin JM \& Pescovitz OH. Definitive diagnosis in children with congenital hypothyroidism. Journal of Pediatrics 2004144 643-647. (https://doi.org/10.1016/j.jpeds.2004.02.020)

22 Mandel S, Hanna C, Boston B, Sesser D \& LaFranchi SH. Thyroxinebinding globulin deficiency detected by newborn screening. Journal of Pediatrics 1993122 227-230. (https://doi.org/10.1016/S00223476(06)80117-4)

23 Jenkins MB \& Steffes MW. Congenital thyroxine binding globulin deficiency: incidence and inheritance. Human Genetics $1987 \mathbf{7 7}$ 80-84. (https://doi.org/10.1007/BF00284719)

24 Hinton CF, Harris KB, Borgfeld L, Drummond-Borg M, Eaton R, Lorey F, Therrell BL, Wallace J \& Pass KA. Trends in incidence rates of congenital hypothyroidism related to select demographic factors data from the United States, California, Massachusetts, New York, and Texas. Pediatrics 2010125 (Supplement 2) S37-S47. (https://doi. org/10.1542/peds.2009-1975D)

25 Pollitt RJ. Evidence or enthusiasm? Why yields from UK newborn screening programmes for congenital hypothyroidism are increasing. Archives of Disease in Childhood 2016101 120-123. (https://doi. org/10.1136/archdischild-2015-309546)

26 Parks JS, Lin M, Grosse SD, Hinton CF, Drummond-Borg M, Borgfeld L \& Sullivan KM. The impact of transient hypothyroidism on the increasing rate of congenital hypothyroidism in the United States. Pediatrics 2010125 (Supplement 2) S54-S63. (https://doi. org/10.1542/peds.2009-1975F)

Received 7 May 2018

Accepted 26 June 2018 